THE INTERNATIONAL

REVIEW OF RESEARCH IN

OPEN AND DISTANCE LEARNING

\title{
Student Access to and Skills in Using Technology in an Open and Distance Learning Context
}
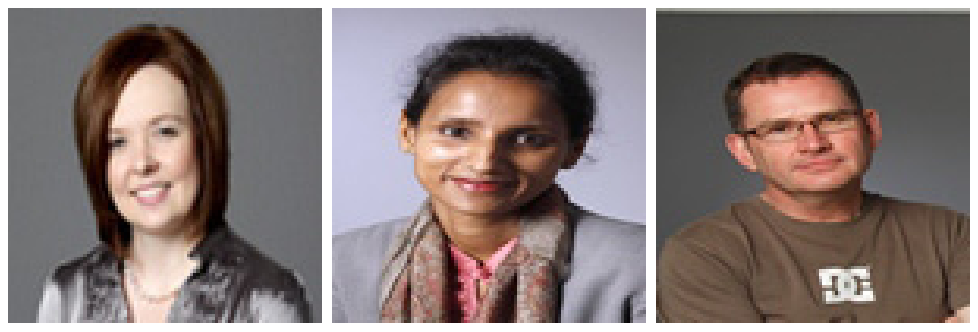

Hanlie Liebenberg, Yuraisha Chetty, and Paul Prinsloo

University of South Africa (Unisa)

\section{Abstract}

Amidst the different challenges facing higher education, and particularly distance education (DE) and open distance learning (ODL), access to information and communication technology (ICT) and students' abilities to use ICTs are highly contested issues in the South African higher education landscape. While there are various opinions about the scope and definition of the digital divide, increasing empirical evidence questions the uncritical use of the notion of the digital divide in South African and international higher education discourses.

In the context of the University of South Africa (Unisa) as a mega ODL institution, students' access to technology and their functional competence are some of the critical issues to consider as Unisa prepares our graduates for an increasingly digital and networked world.

This paper discusses a descriptive study that investigated students' access to technology and their capabilities in using technology, within the broader discourse of the "digital divide." Results support literature that challenges a simplistic understanding of the notion of the "digital divide" and reveal that the nature of access is varied.

Keywords: Access; digital divide; ICT; open distance learning (ODL); skills; University of South Africa (Unisa)

\section{Introduction}

The reality and function of the notion of a digital divide in South Africa as a developing country should be understood against the backdrop of the manifold challenges facing higher education in general (e.g., Barnett, 2000a, 200ob), and particularly higher education in 
South Africa (e.g., Czerniewicz, 2004; Moja \& Hayward, 2000; Kraak, 2000; Teferra \& Altbach, 2004; Waghid, 2002). It is therefore important to situate the debate on the content, scope, and impact of the digital divide in the context of major societal changes in order to address various forms of exclusion prior to the first democratic elections in 1994 based on racial, language, and gender criteria.

Against the broader backdrop of the various challenges facing higher education, and distance education provision in particular, of particular importance is the issue (however contested) of digital inclusion or exclusion. Though ICT use tends to accentuate social disparities between rich and poor (Butcher, 2011, p. 30), access to technologies is part of the "new geographies of power and access that have reconfigured the world" (Czerniewicz, 2004, p. 146). The digital divide is, however, a broad and multilayered phenomenon-with more than just a technological emphasis (Castells, 2009; Czerniewicz \& Brown, 2005; Czerniewicz \& Brown, 2010; Furuholt \& Kristiansen, 2007). The need for a more nuanced and critical understanding of the digital divide is therefore of the utmost importance (e.g., Brown \& Czerniewicz, 2010; Castells, 2009; De Haan, 2004; van Dijk \& Hacker, 2003). The issue of the digital divide is furthermore a "political battlefield" (van Dijk \& Hacker, 2003, p. 321) embedded in broader discourses, such as the employability of graduates (Chetty, 2012). In the general context of critiques regarding our use of notions such as the digital divide, and technology as the most important driver of educational change (see e.g., Friesen, 2008), our research contributes to illustrating that the digital divide is not a simplistic separation between "haves" and "have-nots."

In this paper, we explore variations in the digital divide in the specific context of the University of South Africa. We will first provide an annotated overview of a number of authors who "debunk" (Brown \& Czerniewicz, 2010), "demystify" (Warschauer, 2002), "reconfigure" (Czerniewicz \& Brown, 2010), and "rethink" (Underwood, 2007) or "reconceptualize" (Warschauer, 2002) the notion and function of the digital divide as germane to higher education discourses. The purpose of this article is not to validate or test a particular theoretical model for understanding the digital divide, but we agree, in broad terms, with De Haan's (2004) "multifaceted dynamic model." After providing an overview of the discourse on the digital divide, we provide and analyze findings of a questionnaire that aimed to determine, amongst other things, the nature of students' access to technology and their skills in the specific context of the University of South Africa (Unisa), one of the mega universities of the world.

The significance of this research lies in its contribution to the discourse pertaining to the institutionalization of e-learning in mega open universities (e.g., Panda \& Mishra, 2007).

\section{Research Context}

Unisa is one of the mega universities of the world, with over 350,000 students in 2011. In that year, 282,248 students registered on the Unisa learning management system, myUnisa. As Unisa endeavours to optimize the affordances of technology to increase the effective- 
ness of teaching and learning, it was essential to determine to what extent the notion of the "digital divide" was an accurate reflection of the Unisa student profile.

Prior to 2011, no dedicated Unisa-wide research had been done to determine the level of access and technological capabilities of students. Given Unisa's strategic commitment to increase online provision, this kind of information was becoming important for the institution to reflect on. Clearly, if students do not have access to ICTs, then many of the perceived advantages of using ICTs for education do not translate into reality. Positively, though, the past year has seen an encouraging number of students who have access to myUnisa $\left(282,248\right.$, as of October $\left.27^{\text {th }}, 2011\right)$. However, this does not necessarily translate into full and sustained Internet access.

Within this context, a survey was undertaken to investigate student access to and effective utilization of ICTs. Its broad aim was to provide data that could be used by management to inform decisions within the context of providing effective learner support. In contributing to knowledge about our students, the research also challenged common assumptions about students' access to technology.

\section{Literature Review}

The relationship between advances in technology and their impact on education is wellresearched and documented (e.g., Baldwin, 1998; Herrington \& Oliver, 2003). It is dangerous to assume, however, that technology is the only factor shaping our epistemologies and praxis (see e.g., Friesen, 2008). Advances in technology are also often used as the main differentiator in our conceptual understanding of the various generations of learners in general and in distance education (DE) in particular (Heydenrych \& Prinsloo, 2010, p. 5).

Different theoretical models explore and map various aspects of digital inclusion (e.g., Livingstone \& Helsper, 2007) and exclusion (e.g., Castells, 2009). While researchers can opt to investigate either inclusion or exclusion, we agree with Castells (2009) that inclusion often implies exclusion and that the two concepts are interdependent and linked. Though a number of authors specifically focus on digital inclusion (e.g., Livingstone \& Helsper, 2007; Madon, Reinhard, Roode, \& Walsham, 2009) in the light of the digital divide's prominence in discourses on e-learning in ODL institutions, we attempt to provide an overview of the rather simplistic and un-nuanced definition of the digital divide and implicitly address inclusion as part of that divide. In doing so, we acknowledge that technology and access to technology are shaped by broader global economic, political, and cultural factors. While not everyone is included in this networked society, "everyone is affected [emphasis added] by the processes that take place in the global networks that constitute the social structure" (Castells, 2009, p. 25; also see Czerniewicz, 2004, p. 149).

The idea of the digital divide as part of the "double logic of inclusion and exclusion" (Castells, 2009, p. 25) is pertinent in education, and Castells warns that the one common fundamental form of exercising power is to exclude (Castells, 2009, p. 50). Underwood (2007, p. 213) indicates that the term "digital divide" became the lingua franca in the 1990s, referring 
in general to those who have access to technologies and those with no access. Underwood (2007, p. 214) further states that the notion of the digital divide "is a simplistic model even at an economic level and that it is better to think of information-based economic nodes, within and across regions and within and across countries." A more nuanced understanding of the digital divide must also take into account the "second-level digital divide," capturing the skills dimension of access to technology (Underwood, 2007, p. 214), the different levels of digital literacy, and the divides resulting from the use of English as the language of communication in many online educational platforms (Underwood 2007, p. 215). Warschauer (2002, no page numbers) states that the "notion of the binary divide between the haves and the have-nots is thus inaccurate and can even be patronising as it fails to value the social resources that diverse groups bring to the table."

De Haan (2004, pp. 67-68) points out three problems with current understandings of the digital divide, namely (1) concerns about the simple criterion of access; (2) the fact that the term "digital divide" is mainly descriptive and fails to take into account the factors that cause the divide; and (3) the lack of concern regarding the consequences of differential access. He therefore proposes a multidimensional model in contrast to the general binary understanding of access versus no access. De Haan (2004, p. 71) states that most of the discussion on the digital divide privileges the possession and use of a PC and Internet connection, while "less attention has been paid to digital skills or competence and to motivation." (For a critical discussion of the impact of digital skills and motivation, see De Haan, 2004, pp. 75-76.) See De Haan (2004, p. 70) and van Dijk (2006) for a discussion on different understandings and models mapping the richness of the notion of "access."

Warschauer (2002, no page numbers) summarises criticisms against the notion of the digital divide as follows:

There is not one type of ICT access, but many; the meaning and value of access varies in particular social contexts; access exists in gradations, rather than in bipolar opposition; [...] and acquisition of ICT access is a matter not only of education, but also of power.

\section{Methodology: Considerations and Approach}

This research aimed to evaluate the current status of students' access to and use of various ICTs, as well as their skills and capabilities in using such technologies. It collected baseline information both from students registered on the institutional learning management system (myUnisa) and from those not registered. The research provides a more multilayered understanding and thicker description of access than just the differentiation between access and non-access (e.g., Burbules \& Callister, 2000; Czerniewicz \& Brown, 2005). Underpinning this two-pronged aim was the acknowledgement that while accessto technology is crucial given Unisa's ODL context and strategic commitment to online learning in the very near future, having the ability to use technology is equally important. The statistical analysis is descriptive, using the data to interpret the range of access and capabilities of Unisa students. 
The key research questions were as follows:

- What is the extent of ICT access among Unisa students?

- What are the technological capabilities of Unisa students?

\section{Research Approach}

The sampling approach was non-random and purposive (as described by Johnson \& Christensen, 2008; Teddlie \& Yu, 2007; and Tongco, 2007). The strength of purposive sampling lies in its intentional bias (Tongco, 2007, p. 154). The study aimed to profile two groups of students, namely, students who had already joined myUnisa or used mobile applications to access and use the technology provided by Unisa and those who had not joined myUnisa and did not use technology to interact with the university. Consequently, the methodology was two-fold: a) an online survey option for students who had a myUnisa account and accessed the technology provided by Unisa, and b) a paper-based option for those students without a myUnisa account or with an unused account. The intention was to gain insight into why these students have not joined myUnisa (either via mobile or PC), what the current extent of their technology capabilities are, and what future possibilities might be.

It was recognized that a proportion of students were not accessing technology, with low usage of myUnisa and other technology provided by Unisa being the primary indicators. To avoid bias, it was deemed important to accommodate these students via a paper-based questionnaire. Those regional offices with a low number of students using myUnisa relative to the total number of Unisa students were selected.

The regions across the country in which myUnisa usage was low and which were therefore targeted for the paper-based survey were Polokwane, Giyani, Durban, Richardsbay, Wildcoast, Newcastle, and Mthatha.

\section{Response Rate}

This survey had a positive response rate. Students participated online with great enthusiasm, resulting in over 22,000 fully completed questionnaires. Participation in the regions was slightly lower than expected, however, with just below 500 completed paper-based questionnaires. This number is still statistically valid and resulted in sound analyses. Of the 282,248 online students, 22,216 completed the survey, resulting in an $8 \%$ response rate. Of the 1,400 students sent the paper-based survey, 474 completed it, resulting in a $33 \%$ response rate. To improve response rates, an SMS was also sent to students' mobile phones.

\section{Validity and Reliability}

The validity and reliability of both the research design and survey instrument were reflected upon. External validity, which looks at the representativeness and generalisability of the survey results (Cooper \& Schindler, 1998), was largely addressed by the sampling process. Internal validity, on the other hand, focused on the survey instrument and what it was supposed to measure (Cooper \& Schindler, 1998) given the research objectives. Internal reliability focused on the extent to which the research design and data obtained allowed 
the researchers to draw conclusions about underlying relationships within the data. This was also supported by the theoretical underpinnings of the study. Three specific forms of validity were deemed important for the study, namely, face validity, content validity, and criterion validity. Face validity, while being mostly subjective in nature, was addressed by means of a peer review of the survey instrument amongst both institutional research and ICT staff members. During this process, content validity was also established, confirming the appropriateness of the survey instrument in providing adequate coverage of the investigative questions that guided the study. Criterion validity was confirmed during the exploratory analysis of the data in terms of how the results correlated with other similar research findings within the institution, notably a student profile survey and a student satisfaction survey, which focused in part on students' ICT usage.

\section{Findings and Analyses: Two Themes}

It is pertinent to understand how the analyses were approached and the findings represented. It was acknowledged that within the online group of students who use myUnisa, there could be students who have regular access to a computer and/or the Internet and those who do not have this access. Similarly, within the paper-based group, there could be students with or without access. The results support this and challenge the common assumption that all students using myUnisa have regular Internet access, and that students who are not using myUnisa do not have this access.

While many interesting findings emerged from the survey regarding the current status of student access and use of various ICTs, only the key aspects are discussed. This paper particularly aims to unpack the themes of access to technology in an ODL environment, as well as the ability to use this technology.

In order to gain insight into the survey data, a profiling of the survey respondents was undertaken. The data profiling process in this research project was intended to confirm whether the Unisa student body was adequately represented.

\section{Profile of Respondents}

Figure 1 below reflects the profile of online and paper-based respondents. 


\section{Profile: Respondents \\ Profiling according to methodology}

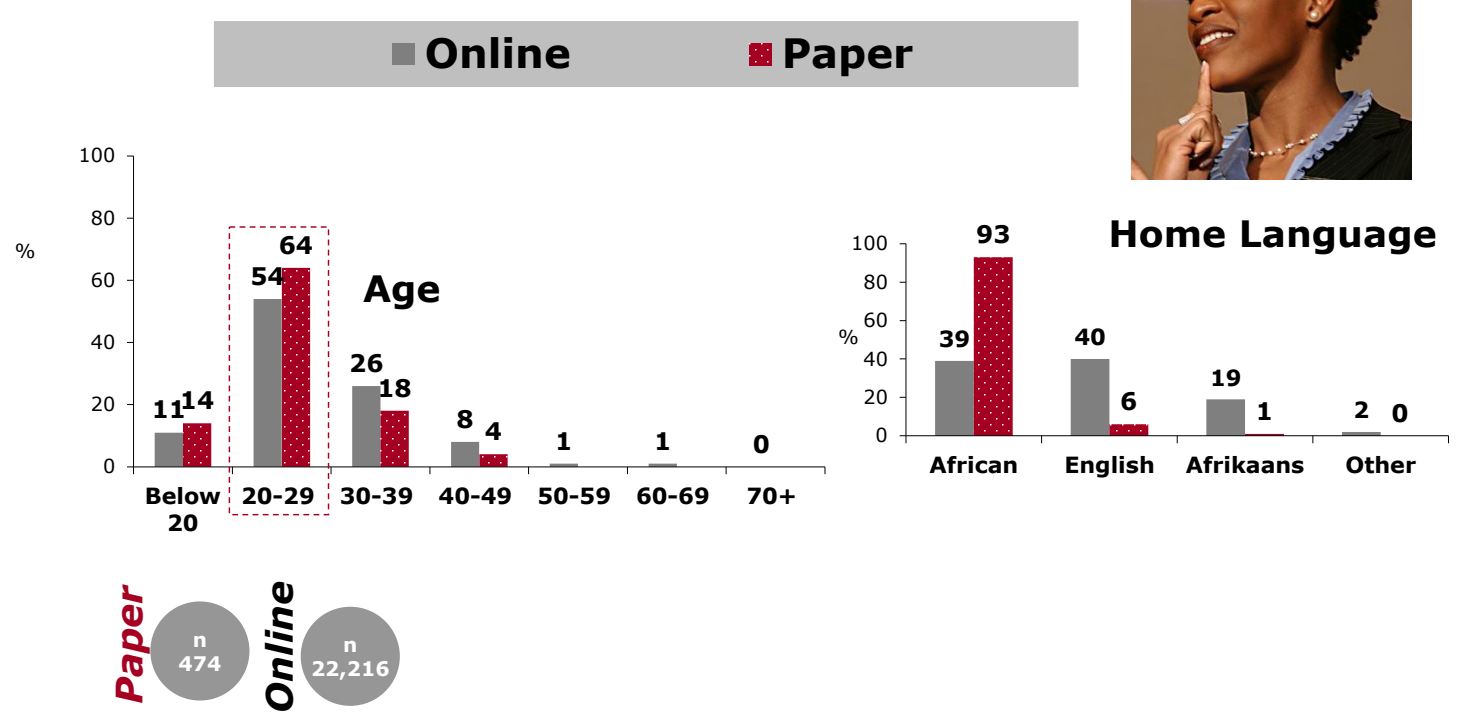

Profiling according to methodology
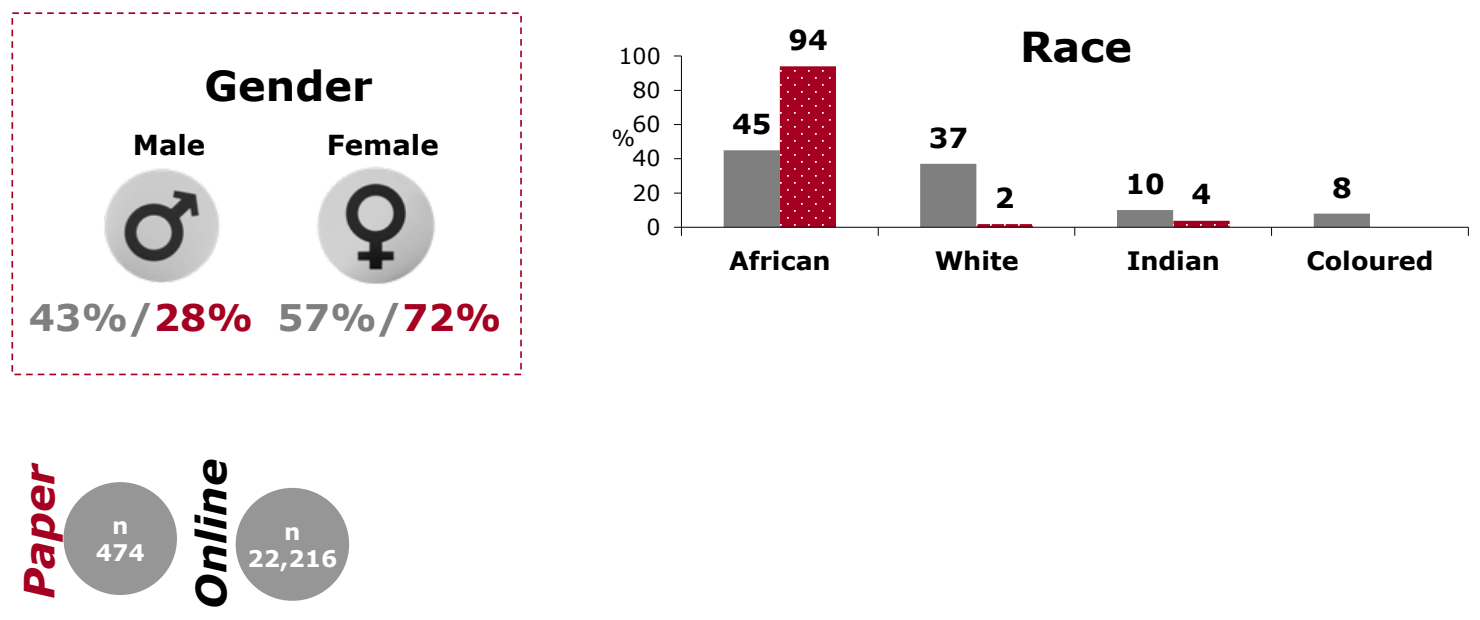

Figure 1. Profiling survey respondents by age, home language, gender, and race.

The majority of participating students were African females, for both the online and the paper-based options, clearly representative of Unisa's current student body, with the majority of students falling into the above-mentioned categories.

Students who participated in the online survey were typically African or white females between 20 and 29 who spoke either English or an African language. Students who participated in the paper-based survey were typically African females between 20 and 29 who spoke an African language. The insight gained from profiling according to the methodology clearly indicated that the participants were representative of Unisa students as most 
of Unisa's students are young African females who reside in Gauteng, Western Cape, and KwaZulu Natal.

\section{Access}

In this section, the theme of access is explored. Upon asking students if they have regular access to a computer (e.g., PC, Mac, laptop, netbook) even if it was not personally owned, all students who participated online indicated that they have regular access to a computer for study purposes (100\%). By comparison, only $52 \%$ of paper-based respondents have access to computers, far less than online respondents.

Further analysis was undertaken to establish the location of access. The analysis revealed that students who have access to a computer mostly access it from home (61\%). Online respondents also make use of work facilities on a frequent basis (53\%), with just 9\% using Internet cafés and $7 \%$ using the Unisa computer laboratory. Paper-based respondents also access a computer mostly from home (39\%). However, unlike online respondents, they make use of Internet café facilities more often (29\%) than work facilities (17\%). Furthermore, 12\% of paper-based respondents access a computer at someone else's home, compared to just $2 \%$ of online respondents.

\section{Access to the Internet.}

Students were asked to indicate if they have regular access to the Internet from a computer even if it is not their own. Results show that $91 \%$ of students who participated online do have regular access to the Internet, clearly an overwhelming majority. However, this means that $9 \%$ of online students do not have regular access to the Internet. By comparison, $46 \%$ of students who completed the paper-based survey have access, with $54 \%$ not having access. Clearly, both groups of students have access and do not have access to the Internet, debunking the assumption that all online students have regular access to the Internet and that all paper-based respondents are likely not to have regular access. This confirms research by, amongst others, Brown and Czerniewicz (2010), Czerniewicz (2004), Underwood (2007), and Warschauer (2002), supporting the idea that access to computers and the Internet is a multidimensional phenomenon and that the strict binary of "haves" and "have-nots" is not a usable construct.

Online students who have access to the Internet mostly access it from home (57\%) and work (51\%). However, paper-based respondents in most cases make use of Internet café facilities (34\%), followed by the Unisa computer laboratories (25\%). Research results also reveal that students who have home computers are more likely to have Internet access.

It is not surprising that the mobile phone is reducing reliance on public Internet facilities. Evident from the findings is that the mobile phone is the third most popular option for online students to access the Internet (11\%), followed by Internet café facilities (10\%). Furthermore, $10 \%$ of paper-based respondents make use of their mobile device to connect to the Internet, indicating that respondents from both sampling methods increasingly use their mobile phone to access the Internet. 
ADSL is the most used type of Internet access among the online group (39\%), followed by $3 \mathrm{G}(35 \%)$, a company local area network (32\%), and mobile devices (16\%). Within the paper-based group, however, $51 \%$ indicated that they do not know the type of Internet access they are using. This lack of knowledge could be attributed to a lack of ownership of a personal computer. It is less likely that these students would know the type of Internet access used as we have discovered that they are mainly accessing the Internet from Internet café facilities. However, $18 \%$ do access via ADSL connections, followed by $3 \mathrm{G}$ (14\%) and mobile devices (12\%).

\section{Reasons for no access to the Internet.}

For the online respondents, a lack of access to a personal computer (28\%) and affordability (25\%) were the main reasons they did not have Internet access, followed by not being allowed to access the Internet at work (11\%).

Paper-based respondents provided similar reasons for not being able to access the Internet. A lack of access to a personal computer (25\%) and affordability (22\%) were the two main reasons students do not have Internet access, followed by not being able to afford the travel costs to a facility with a connection (11\%). Clearly, from the results for both online and paper-based students, the lack of a personal computer and affordability are the main obstacles to access to the Internet.

\section{Access to the Internet using a mobile phone.}

It is evident that the vast majority (82\%) of online respondents own a mobile device that is capable of accessing the Internet. By comparison, only $55 \%$ of paper-based respondents own a mobile device that is capable of accessing the Internet, which nevertheless is still a large number of students making use of mobile connectivity.

Respondents were further probed on the frequency with which they use the Internet. A total of $62 \%$ of online respondents make use of their mobile phone to access the Internet daily (41\%) or weekly (21\%). By comparison, $43 \%$ of paper-based respondents never use their mobile phone to access the Internet. However, a total of $44 \%$ of paper-based respondents do make frequent use of their mobile phone to access the Internet-this occurs daily (21\%), several times a week (14\%), or weekly (9\%).

It is important to note that affordability might inhibit efforts to leverage the use of mobile technology for study purposes. While students might access the Internet via their mobile phones for personal activities and be willing to pay for this usage, they may be less likely to be able to afford to use mobile technology for study or learning activities.

\section{Profiling according to access.}

As analysis progressed, it became more pertinent to explore whether the profiles of students with access or without access to the Internet were similar or different (see Figure 2). 
The profiles of both groups of students were representative of our current student population. The profile of respondents by various demographics therefore closely mirrors the distribution of these demographics in the student population at Unisa. This is reflected in Figure 2 below.

\section{Profile: Access \\ Profiling according to access}
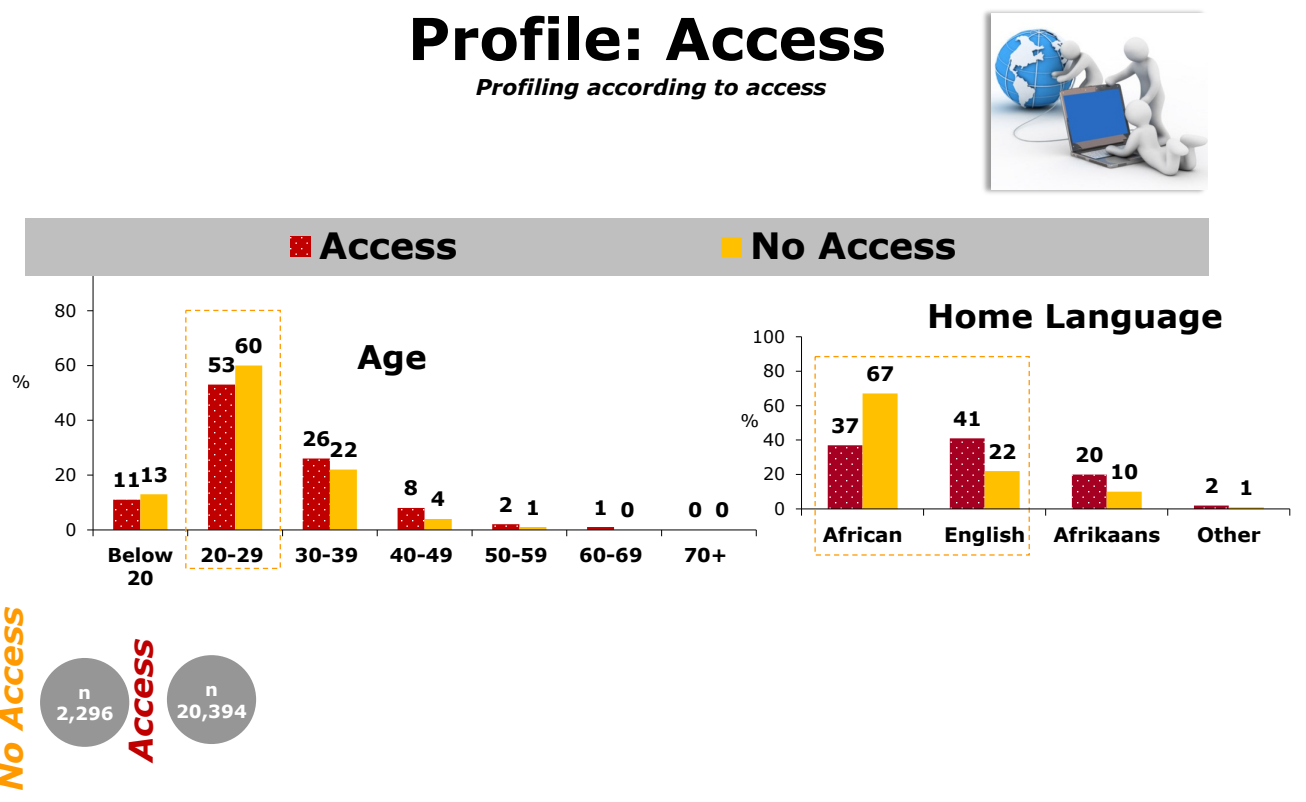

Profiling according to access

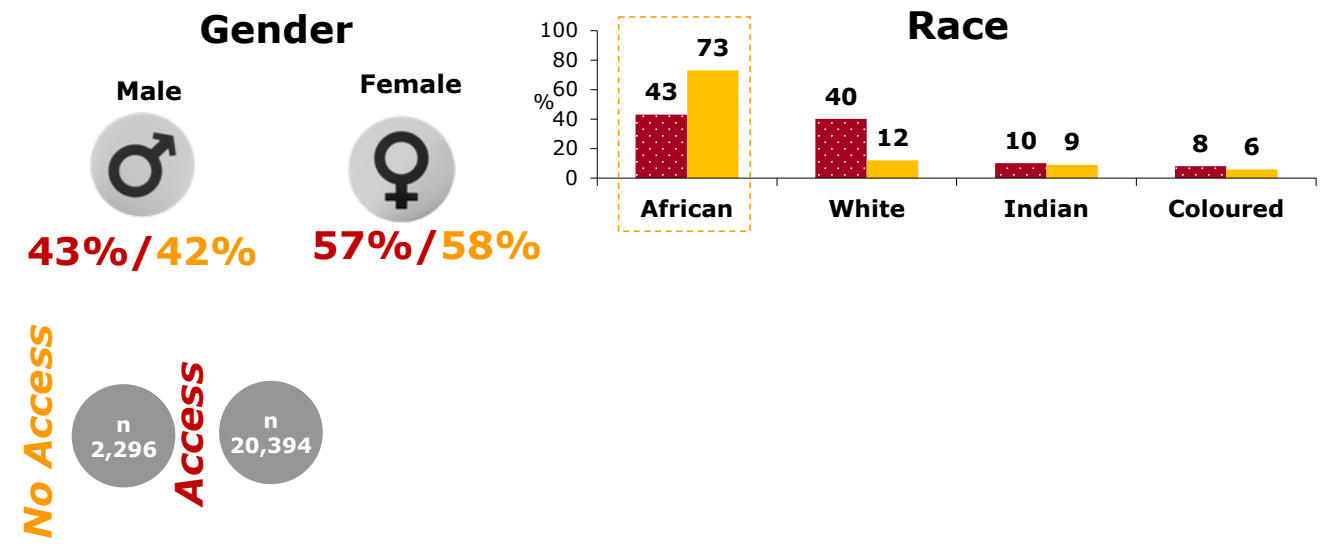

Figure 2. Profile according to access: demographics.

Figure 2 reveals that students who have access are typically African and white females between 20 and 29 who speak either English or an African language. The finding that the access group includes African students questions assumptions about access being racially skewed. Students who have regular access to the Internet also have a very similar profile to those students who participated online.

Students who do not have access are typically African females (73\%) between 20 and 29 who speak an African language. Clearly, non-access is as prevalent among female African 
students as is access. The profile of students with no access to the Internet mirrors the profile of students who participated via the paper-based option.

It was also important to determine the regional distribution of access and no access, and this is reflected in Figure 3 .

\section{Profile: Access}

Profiling according to access

\begin{tabular}{|l|l|l|}
\hline Province & Access & No Access \\
\hline Gauteng & $\mathbf{4 6} \%$ & $38 \%$ \\
\hline KwaZulu Natal & $\mathbf{1 4 \%}$ & $\mathbf{2 2} \%$ \\
\hline Western Cape & $\mathbf{1 3} \%$ & $\mathbf{8} \%$ \\
\hline Mpumalanga & $\mathbf{4 \%}$ & $4 \%$ \\
\hline Eastern Cape & $\mathbf{4 \%}$ & $\mathbf{4} \%$ \\
\hline Limpopo & $\mathbf{4 \%}$ & $\mathbf{7 \%}$ \\
\hline North West & $\mathbf{4 \%}$ & $\mathbf{5 \%}$ \\
\hline Free State & $\mathbf{2 \%}$ & $\mathbf{2} \%$ \\
\hline Northern Cape & $\mathbf{1 \%}$ & $\mathbf{1} \%$ \\
\hline Unknown & $\mathbf{9 \%}$ & $7 \%$ \\
\hline
\end{tabular}

Access

-Pretoria/Sunnyside No Access -Johannesburg Pretoria/Sunnyside -Florida -Ekurhuleni -Durban -Parow

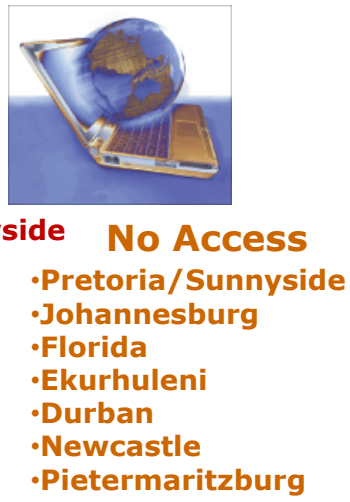

-Pietermaritzburg

Figure 3. Profile according to access: regional distribution.

Figure 3 reveals that students who have regular access reside in main metropolitan areas in Gauteng, KwaZulu Natal, and the Western Cape, amongst others. Similarly, students who do not have regular access reside in main metropolitan areas in Gauteng and KwaZulu Natal.

Even in main metropolitan areas such as Pretoria and Benoni, some students struggle with Internet access, mainly because of the cost involved and not necessarily because of infrastructure or location. This again challenges a common assumption that non-access is more prevalent in rural areas.

\section{Capabilities}

Following access, the second key theme explored was the ability of students to use technology. This was based on students' self-reports of their abilities. 


\section{Downloading ability.}

Can you download and play videos and audio files on the computer you use regularly?

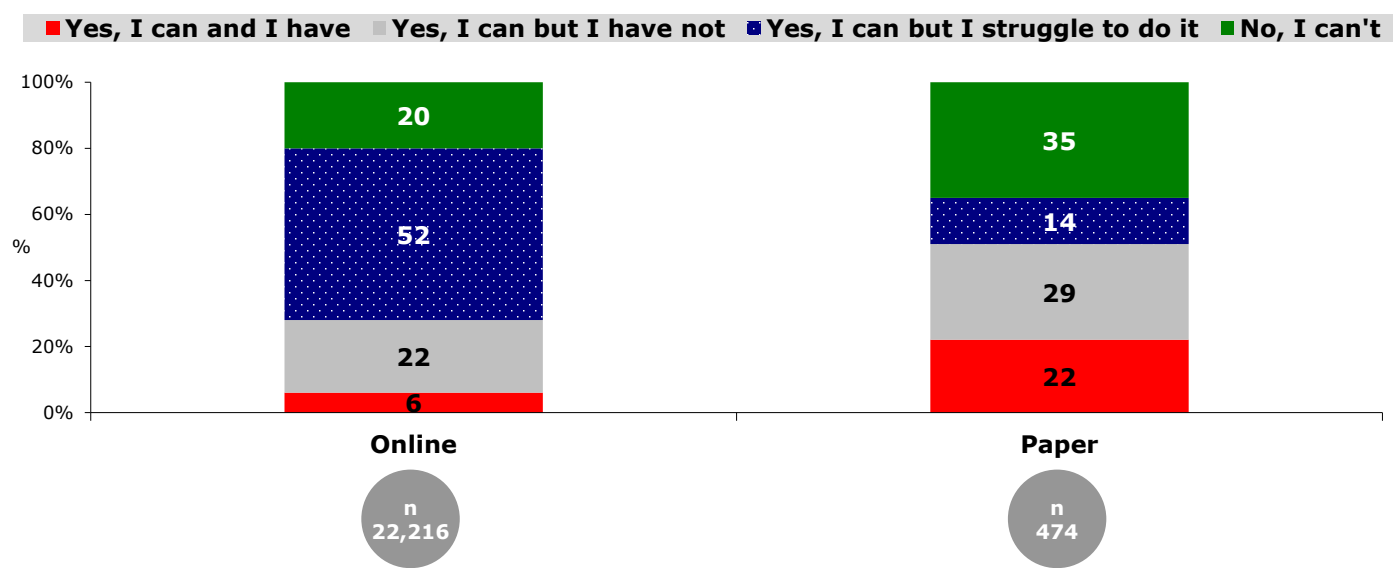

Figure 4. Downloading ability (student self-report).

Figure 4 reveals that online respondents mostly indicated that they do download and play video and audio files but struggle to do so (52\%). However, more paper-based respondents (35\%) than online respondents (20\%) indicated that they cannot do it at all. The reasons for this are illustrated in Figure 5 .

If you can't or struggle to do so, why is this?

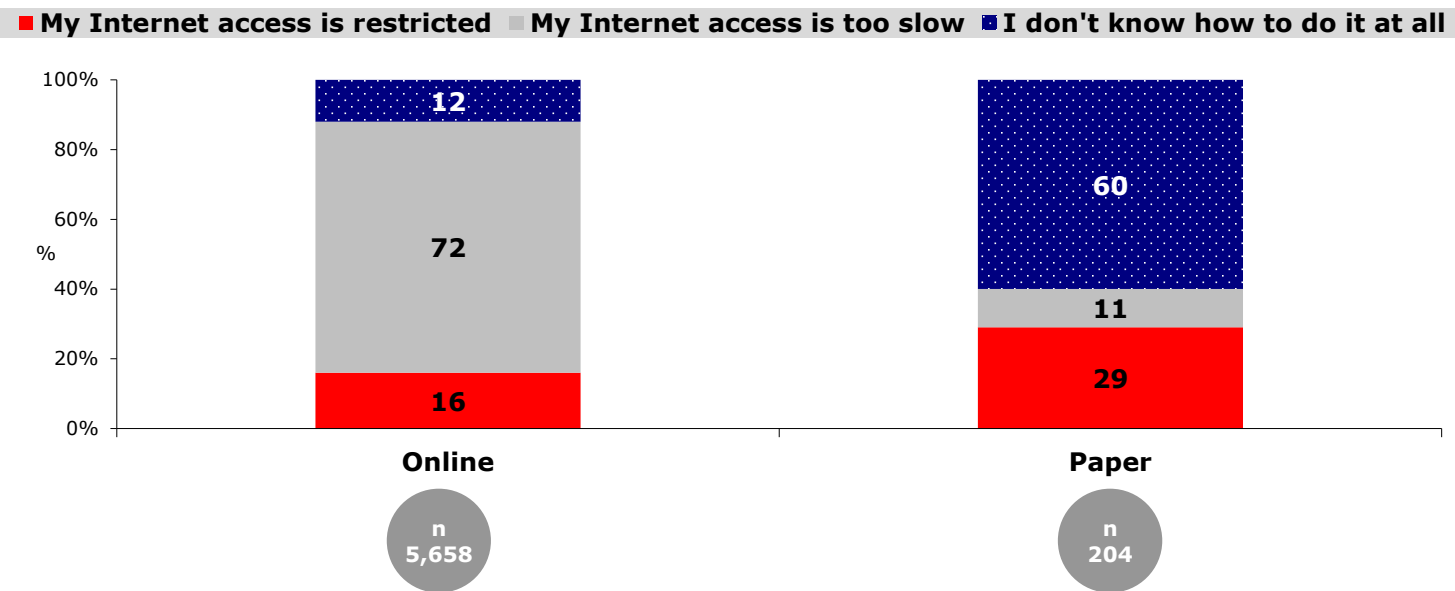

Figure 5. Reasons for "I can, but struggle" and "I can't" (student self-report).

Figure 5 reveals that among the online group, students struggle mainly due to slow Internet access. On the contrary, the paper-based group indicated that they struggle due to a lack of know-how. The latter reflects a lack of technical ability among this group of students, which will need to be addressed in view of Unisa's strategic intent to move toward an online-only policy by 2015. Some online courses at Unisa will make use of videos and audio files and could potentially inhibit student success if students are not ICT proficient. Furthermore, students who do not own a personal computer or cannot afford access to the Internet, as 
results revealed, are likely to be slower to build and develop the necessary skills required.

\section{Ability to use software packages, platforms, and IT resources.}

Students were asked to indicate their ability to use specific software packages via a selfrating scale. According to Seymour and Fourie (2004), an attempt is being made to create ICT-literate individuals, with an effort being made into providing access to ICTs. Regardless, researchers have argued that access alone does not lead to effective usage and that factors such as sociocultural and behavioural issues need to be addressed as well. Clearly, students who participated online are very comfortable with e-mail (93\%), Internet browsers (92\%), and Internet search engine platforms (93\%). As expected, these students can also navigate through the myUnisa site very well (91\%). Of concern is the low rating with regard to the Unisa online library (45\%), as students clearly struggle to make use of this very important resource.

The pattern shifts for the paper-based respondents as they are less comfortable with Internet search engine platforms (48\%) and e-mail (43\%). These students struggle to use the myUnisa site, with just $38 \%$ rating their ability as very good. They also scored themselves very low (25\%) in terms of their ability to use the Unisa online library.

\section{Ability to use a range of other resources from a mobile phone.}

Students' ability to use a range of other resources from a mobile phone was also investigated and this is based on their self-reports. The responses for online students are reflected in Figure 6.

Please rate your ability to use the following applications on/from your mobile device.

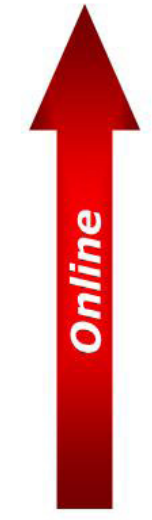

Ability

\begin{tabular}{|c|c|}
\hline Resources & Top Box Score \\
\hline Instant messages & Very Good- $\mathbf{5 2} \%$ \\
\hline SMS & Very Good- $92 \%$ \\
\hline E-mail & Very Good- $\mathbf{8 0} \%$ \\
\hline Micro-blogs (Twitter) & Very Good- $37 \%$ \\
\hline $\begin{array}{l}\text { Social networking } \\
\text { websites (Facebook) }\end{array}$ & Very Good- $63 \%$ \\
\hline News, weather, sports & Very Good- 64\% \\
\hline Blogs & Very Good- $37 \%$ \\
\hline Maps & Very Good- $52 \%$ \\
\hline Banking, shopping & Very Good- $56 \%$ \\
\hline Flickr, Picasa & Very Good- $30 \%$ \\
\hline Download or stream music & Very Good- $41 \%$ \\
\hline Download or watch videos & Very Good- $40 \%$ \\
\hline Download or play games & Very Good- $36 \%$ \\
\hline Listen to radio & Very Good- $54 \%$ \\
\hline
\end{tabular}

Figure 6. Ability to use a range of other resources on/from a mobile device (student selfreport). 
It is clear that online students have the ability to make use of SMS and e-mail applications.

The responses for paper-based students are reflected in Figure 7.

Please rate your ability to use the following applications on/from your mobile device.

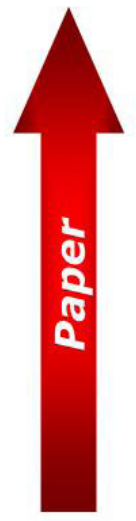

Ability

\begin{tabular}{|l|l|}
\hline Resources & Top Box Score \\
\hline Instant messages & Very Good- 22\% \\
\hline SMS & Very Good- $\mathbf{8 6} \%$ \\
\hline E-mail & Very Good- 43\% \\
\hline Micro-blogs (Twitter) & Very Good- 18\% \\
\hline $\begin{array}{l}\text { Social networking } \\
\text { websites (Facebook) }\end{array}$ & Very Good- $\mathbf{4 7} \%$ \\
\hline News, weather, sports & Very Good- $\mathbf{4 3} \%$ \\
\hline Blogs & Very Good- 21\% \\
\hline Maps & Very Good- 20\% \\
\hline Banking, shopping & Very Good- 25\% \\
\hline Flickr, Picasa & Very Good- 20\% \\
\hline Download or stream music & Very Good- 28\% \\
\hline Download or watch videos & Very Good- 33\% \\
\hline Download or play games & Very Good- 26\% \\
\hline Listen to radio & Very Good- 67\% \\
\hline
\end{tabular}

Figure 7. Ability to use applications on/from a mobile device (student self-report).

Figure 7 reveals that paper-based respondents have lower levels of proficiency in using email, which could be due to lower levels of access among this group.

\section{Discussion}

Although the notion of the digital divide has been deconstructed and debunked by a number of authors (e.g., Czerniewicz \& Brown, 2005; Czerniewicz \& Brown, 2010; Furuholt \& Kristiansen, 2007), the issue of digital inclusion and exclusion continues to play an important role in the rhetoric of higher education (e.g., Friesen, 2008) and more specifically in distance education (e.g., Panda \& Mishra, 2007).

Evident from this research, students who are active on myUnisa and who completed the survey online have regular access to ICTs for educational purposes (91\%). Contrary to popular belief that students participating online have access to the Internet, $9 \%$ of these students indicated that they do not have regular access to ICTs. This finding supports the view that the notion of "haves" and "have-nots" as a "bipolar societal split" (Warschauer, 2002) has no empirical basis.

The research also found that students who are not active on myUnisa and who completed the paper-based survey have less access to ICTs for educational purposes (46\%). Survey results indicated that the majority of online students access the Internet either from home 
(57\%) or work (51\%). According to the results of the 2009 ICT survey, the majority of students accessed the Internet from work. Based on the 2011 results, there has clearly been a shift, with more students having private access to the Internet from home.

With regard to the Internet, access is only one aspect. Other factors, such as the quality of resources (modem/PC) and connectivity (bandwidth), should be considered. This finding confirms the importance of resources in the bigger picture of "access" as proposed by De Haan (2004, p. 70). As indicated by the profiling results, regardless of the region in which students are located, affordability is the main determinant of access to the Internet. Even in main metropolitan areas such as Pretoria and Benoni, some students struggle with Internet access, mainly because of the cost involved and not necessarily as a result of infrastructure or location. This fact will have to be considered within the context of broader student initiatives to improve success, retention, throughput, and graduation rates.

The use of mobile phones is reducing the importance of public Internet access facilities. This is evident by the finding that the mobile phone is the third most popular option for online students to access the Internet. The increasing reliance upon the mobile phone and applications that lend themselves to regular use during the course of a student's studies indicates that the mobile phone is a key entry point for Internet adoption (e.g., Alexander, 2004; Mcconatha, Praul, \& Lynch, 2008). Mobile phones are being increasingly used by both white and African students to access the Internet (Shapshak, 2012). The change that smartphones bring is computing power in the palm of students' hands, resulting in Internet connectivity almost anywhere in South Africa. This will have a profound influence on how Unisa develops platforms in order for students to be able to use various student-facing systems, such as online registration, myUnisa, and the online library, to mention but a few. Results indicate that the majority of online students access the Internet either from home or work, and this could have implications for ICT service delivery and support functions provided by Unisa. Aspects that will need to be taken into account are the times of day or night that students are active online. According to results, students tend to access more often from home, which results in increased activity online during non-working hours.

Results further reveal that not all students are ICT proficient in the Unisa environmentthis will pose a challenge for learning in an ODL environment. While increased reliance on ICTs in HE assumes that students are ICT literate, it also assumes that all learners have similar levels of ICT proficiency. In the Unisa environment, this is not true and can potentially lead to deepening ICT-literacy inequalities.

Students who participated online (majority African) have better levels of proficiency than students who completed the paper-based survey (majority African). Despite the increased use of ICTs in education and for entertainment purposes, many university students still lack the ICT literacy needed for the completion of university assignments (Seymour \& Fourie, 2004). It is clear that access alone does not lead to effective usage, and the focus on enhancing student ICT proficiency remains a key objective in the ODL environment. Concerns remain that the use of ICTs in education will widen existing divisions along economic, social, cultural, and geographic lines. The introduction of ICTs in education, when done 
without careful deliberation, can result in the further marginalization of those who are already underserved and/or disadvantaged (Brown \& Czerniewicz, 2010). In the Unisa environment, continued interventions and support are required to decrease inequalities and optimise student access to and effective utilization of ICTs.

\section{Conclusion}

Reflecting on exclusion and inclusion in a networked society, Castells (2009) wrote:

Even with growing access to the Internet and to wireless communication, abysmal inequality in broadband access and educational gaps in the ability to operate in a digital culture tend to reproduce and amplify class, ethnic, race, age, and gender structures of social domination between countries and within countries. (p. 57)

Though our research was done in the specific context of an ODL institution in a developing economy, it highlights and confirms that digital access is nuanced and that we should not only understand, irrespective of context, how digital access and skills amplify and perpetuate existing societal inequalities within and between countries. As the cumulative effects of globalization and information-flows on higher education become more apparent (Barnett, 200ob), the digital divide becomes not only a concept germane to developing world contexts, but one that increasingly shapes and impacts all societies where global and local trends and forces interact, displace, exclude, and include.

Among the many challenges facing higher education and ODL provision in developing world contexts, the questions raised by the continued prominence of the digital divide need to be taken seriously, but also reflected on critically. Constructs such as the digital divide can be used to sustain an unwillingness by faculty (Panda \& Mishra, 2007) to accept that technology is shaping higher education and that the way we see and understand knowledge and knowledge creation and validation has changed forever (e.g., Barnett, 2000a, 2000b). On the other hand, we cannot negate the fact that we should understand the issue of access to technology in the wider societal context of exclusion and inclusion (Castells, 2009).

This research provides evidence that the construct of the digital divide as a "bipolar societal split" (Warschauer, 2002) has very little, if any, empirical basis in the context of Unisa. Access to technologies and the skills to use these technologies vary and refuse to fit neatly into a binary model of "haves" and "have-nots." Authors such as Brown and Czerniewicz (2010), Czerniewicz and Brown (2005), De Haan (2004), van Dijk (2006), and Warschauer (2002) provide findings to support an understanding of access to technology as a multifaceted, dynamic construct embedded in broader socioeconomic, political, environmental, and technological realities. 


\section{References}

Alexander, B. (2004). Going nomadic: Mobile learning in higher education. EDUCAUSE Review, 39(5), 28-35. Retrieved from http://www.educause.edu/ero/article/ going-nomadic-mobile-learning-higher-education

Baldwin, R. G. (1998). Technology's impact on faculty's life and work. New Directions for Teaching and Learning, 76, 7-21. Retrieved from http://onlinelibrary.wiley.com/ doi/10.1002/tl.7601/pdf

Barnett, R. (2000a). Thinking the university, again. Educational Philosophy and Theory, 32(3), 319-326.

Barnett, R. (200ob). University knowledge in an age of supercomplexity. Higher Education, 40, 409-422.

Brown, C., \& Czerniewicz, L. (2010). Debunking the "digital native": Beyond digital apartheid, towards digital democracy. Journal of Computer Assisted Learning, 26, 357-369.

Burbules, N. C., \& Callister, T. A. (2000). Watch IT: The risks and promises of information technologies in education. Oxford: Westview.

Butcher, N. (2011). A basic guide to open educational resources (OER). Vancouver: Commonwealth of Learning.

Castells, M. (2009). Communication power. Oxford: Oxford University Press.

Chetty, Y. (2012). Graduateness and employability within the higher education environment: A focused review of the literature. In M. Coetzee, J. Botha, N. Eccles, N. Holtzhausen, \& H. Nienaber (Eds.), Developing student graduateness and employability: Issues, provocations, theory and practical application (pp. 5-24). Johannesburg: Knowledge Resources.

Cooper, D. R., \& Schindler, P. (1998). Business research methods. New York: Irwin/McGraw-Hill.

Czerniewicz, L. (2004). Cape of storms or Cape of Good Hope? Educational technology in a changing environment. British Journal of Educational Technology, 35(2), $145^{-158 .}$

Czerniewicz, L., \& Brown, C. (2005). Access to ICT for teaching and learning: From single artefact to interrelated resources. International Journal of Education and Development using Information and Communication Technology, 1(2), 42-56.

Czerniewicz, L., \& Brown, C. (2010). Born into the digital age in the south of Africa: The reconfiguration of the "digital citizen.” In L. Dirckinck-Holmfeld, V. Hodgson, C. 
Jones, D. McConnell, \& T. Ryberg (Eds.), Proceedings of the 7th International Conference on Networked Learning, Aalborg. Retrieved from http://www.lancs. ac.uk/fss/organisations/netlc/past/nlc2010/abstracts/PDFs/Czerniewicz.pdf

De Haan, J. (2004). A multifaceted dynamic model of the digital divide. IT \& Society, 1(7), 66-88.

Friesen, N. (2008, June). Critical theory: Ideology critique and the myths of e-learning. Ubiquity, 2008. Retrieved from http://dl.acm.org/citation.cfm?id=1386860

Furuholt, B., \& Kristiansen, S. (2007). The rural-urban digital divide? Regional aspects of Internet use in Tanzania. The Electronic Journal of Information Systems in Developing Countries, 31(6), 1-15.

Herrington, J., \& Oliver, R. (2003). Patterns of engagement in authentic online learning environments. Australian Journal of Educational Technology, 19(1), 59-71. Retrieved from http://www.ascilite.org.au/ajet/ajet19/herrington.html

Heydenrych, J., \& Prinsloo, P. (2010). Revisiting the five generations of distance education: Quo vadis? Progressio, 32(1), 5-26.

Johnson, B., \& Christensen, L. (2008). Educational research: Quantitative, qualitative, and mixed approaches ( $3^{\text {rd }}$ ed.). London: SAGE Publications.

Kraak, A. (Ed.) (2000). Changing modes: New knowledge production and its implications for higher education in South Africa. Pretoria: HSRC Press.

Livingstone, S., \& Helsper, E. (2007). Gradations in digital inclusion: Children, young people, and the digital divide. New Media Society, 9, 671-696.

Madon, S., Reinhard, N., Roode, D., \& Walsham, G. (2009). Digital inclusion projects in developing counties: Processes of institionalization. Information Technology for Development, 15(2), 95-107.

Mcconatha, D., Praul, M., \& Lynch, M. J. (2008). Mobile learning in higher education: An empirical assessment of a new educational tool. The Turkish Online Journal of Educational Technology-TOJET, 7(3). Retrieved from http://davidwees.com/ etec522/sites/default/files/mobile\%2olearning\%20in\%2ohigher\%20education. pdf

Moja, T., \& Hayward, F. (2000).Higher eduction policy development in contemporary South Africa. Higher Education Policy, 13(1), 335-359.

Panda, S., \& Mishra, S. (2007). E-learning in a mega open university: Faculty attitude, barriers, and motivators. Educational Media International, 44(4), 323-338.

Seymour, L., \& Fourie, R. (2004). ICT literacy in higher education: Influences and inequal- 
ity. Proceedings of 2004 Annual Research Conference of the South African Institute of Computer Scientists and Information Technologists on IT Research in Developing Countries, South Africa. Retrieved from http://web.up.ac.za/ecis/ SACLA2010PR/SACLA2010/Papers/SACLA002.pdf

Shapshak, T. (2012, October 4). Africa not just a mobile-first continent-it's mobile only. Message posted to http://www.cnn.com/2012/10/04/tech/mobile/africa-mobile-opinion/

Teddlie, C., \& Yu, F. (2007). Mixed methods sampling: A typology with examples. Journal of Mixed Methods Research, 1, 77-100.

Teferra, D., \& Altbach, P. G. (2004). African higher education: Challenges for the $21^{\text {st }}$ century. Higher Education, 47, 21-50.

Tongco, M. D. (2007). Purposive sampling as a tool for informant selection. Ethobotany Research \& Applications, 5, 147-158.

Underwood, J.D.M.(2007). Rethinking the digital divide: impacts on student-tutor relationships. European Journal of Education, 42(2), 213-222.

van Dijk, J., \& Hacker, K. (2003). The digital divide as a complex and dynamic phenomenon. The Information Society, 19, 315-326.

vanDijk, J.A.G.M. (2006). Digital divide research, achievements and shortcomings. Poetics, 34(4-5), 221-235.

Waghid, Y. (2002). Knowledge production and higher education transformation in South Africa: Towards reflexivity in university teaching, research, and community service. Higher Education, 43, 457-488.

Warschauer, M. (2002). Reconceptualising the digital divide. First Monday, 7(7). Retrieved from http://ojphi.org/htbin/cgiwrap/bin/ojs/index.php/fm/article/ viewArticle/967

Warschauer, M. (2003, August). Demystifying the digital divide. Scientific American, 4247.

\section{Athabasca University $\mathbf{C}$}

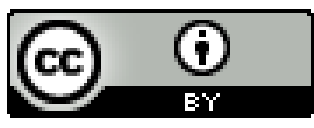

